\title{
Detecting biomarkers of secondhand marijuana smoke in young children
}

\author{
Karen M. Wilson ${ }^{1,2}$, Michelle R. Torok ${ }^{2,3}$, Binnian Wei ${ }^{4}$, Lanqing Wang ${ }^{4}$, Michelle Robinson ${ }^{5}$, Connie S. Sosnoff ${ }^{4}$ and \\ Benjamin C. Blount ${ }^{4}$
}

BACKGROUND: The impact of secondhand marijuana smoke exposure on children is unknown. New methods allow detection of secondhand marijuana smoke in children.

METHODS: We studied children ages 1 mo to 2 y hospitalized with bronchiolitis in Colorado from 2013 to 2015. Parents completed a survey, and urine samples were analyzed for cotinine using LC/MS/MS (limits of detection $0.03 \mathrm{ng} / \mathrm{ml}$ ) and marijuana metabolites including $\mathrm{COOH}-\mathrm{THC}$ (limits of detection $0.015 \mathrm{ng} / \mathrm{ml}$ ).

RESULTS: A total of 43 subjects had urine samples available for analysis. Most (77\%) of the subjects were male, and 52\% were less than 1 y of age. $\mathrm{COOH}-\mathrm{THC}$ was detectable in $16 \%$ of the samples analyzed ( $\mathrm{THC}+$ ); the range in $\mathrm{COOH}-\mathrm{THC}$ concentration was $0.03-1.5 \mathrm{ng} / \mathrm{ml}$. Two subjects had levels $>1 \mathrm{ng} / \mathrm{ml}$. Exposure did not differ by gender or age. Non-white children had more exposure than white children (44 vs. 9\%; $P<0.05$ ). $56 \%$ of children with cotinine $>2.0 \mathrm{ng} / \mathrm{ml}$ were $\mathrm{THC}+$, compared with $7 \%$ of those with lower cotinine $(P<0.01)$.

CONCLUSION: Metabolites of marijuana smoke can be detected in children; in this cohort, 16\% were exposed. Detectable $\mathrm{COOH}-\mathrm{THC}$ is more common in children with tobacco smoke exposure. More research is needed to assess the health impacts of marijuana smoke exposure on children and inform public health policy.

T The use of marijuana has been increasing in both acceptability and legality in the past $15 \mathrm{y}$. Currently 23 states plus Guam allow the legal use of marijuana for medical reasons, and 4 states plus Washington, DC have legalized recreational use. In 2013, 5.7 million persons aged 12 or older used marijuana on a daily or almost daily basis in the previous $12 \mathrm{mo}$; this represents an increase from the 3.1 million daily or almost daily users in 2006 (1). While marijuana can also be aerosolized, or ingested as hash oil or leaf, combusted marijuana is still the most common form of consumption (2). A recent analysis of data from the US National Health and Nutrition Examination Survey (NHANES) finds that daily marijuana users have higher levels of combustion biomarkers (e.g., volatile organic compounds and polycyclic aromatic hydrocarbons) than nonusers (3). Exposure to combustion products likely extends to adjacent nonusers, as has been shown for tobacco smoke (4). Most states with legal marijuana use do not have any restrictions on combustible marijuana use in the presence of children.

While there is clear research on the dangers of secondhand tobacco smoke (4), the impact of secondhand marijuana smoke on children has not yet been studied. There are several studies suggesting that marijuana smoke contains particulate matter known to be harmful when inhaled, in addition to other toxic and carcinogenic chemicals, such as volatile organic compounds, polycyclic aromatic hydrocarbons, and aromatic amines $(5,6)$. A recent study in rats found that brief exposure to secondhand marijuana smoke impaired endothelial function (7). Studies in adults have demonstrated that it is possible to feel the effects of marijuana smoke from intense secondhand marijuana smoke exposure (8). Children could be exposed to secondhand marijuana smoke when parents or other household contacts smoke marijuana indoors, similar to the way children who live with tobacco smokers are exposed to secondhand tobacco smoke (9). Since the co-use of marijuana and tobacco is high (10), there is a significant possibility that children are being exposed to both substances.

Marijuana contains two primary active components: $\Delta 9$-tetrahydrocannabinol (THC), and cannabidiol (CBD) (10). THC is the primary psychoactive chemical in marijuana; $\mathrm{CBD}$ is nonpsychoactive, but has other demonstrated effects (11). Currently available analytical methods are not sensitive enough to detect exposure to secondhand marijuana smoke. This is sufficient when testing for active marijuana use. However, in the case of secondhand marijuana smoke, the levels of these chemicals in urine are usually too low to be detected. The Centers for Disease Control and Prevention has recently developed a new high sensitivity assay to monitor trace levels of marijuana biomarkers at levels that might be seen in secondhand marijuana smoke exposure, allowing us to more accurately assess whether children have been exposed (12). The objectives of

\footnotetext{
'Department of Pediatrics, Icahn School of Medicine at Mount Sinai, New York, New York; ${ }^{2}$ American Academy of Pediatrics Julius B. Richmond Center of Excellence, Elk Grove Village, Illinois; ${ }^{3}$ ACCORDS, University of Colorado, Aurora, Colorado; ${ }^{4}$ Tobacco and Volatiles Branch, Division of Laboratory Sciences, National Center for Environmental Health, Centers for Disease Control and Prevention, Atlanta, Georgia; ${ }^{5}$ Pediatric Hospital Medicine, Children's Hospital, Aurora, Colorado. Correspondence: Karen M. Wilson (Karen. wilson@mssm.edu)

Received 21 June 2016; accepted 4 October 2016; advance online publication 18 January 2017. doi:10.1038/pr.2016.261
} 
this study were to (i) document the presence of metabolites of secondhand marijuana smoke exposure in children admitted to a hospital in Colorado for treatment of bronchiolitis, and (ii) to examine the association between secondhand marijuana and tobacco smoke exposure in this population.

\section{METHODS}

This study was a secondary analysis of urine samples and questionnaire data collected for a study examining the impact of secondhand tobacco smoke exposure on children hospitalized for bronchiolitis.

\section{Participants/Procedures}

We recruited previously healthy children ages 1 mo to 2 y who were admitted to Children's Hospital Colorado with a diagnosis of bronchiolitis from 2013 to 2015; Recreational marijuana use became legal in Colorado on 1 January 2014. We obtained urine samples from the child within $24 \mathrm{~h}$ of admission; these were placed in a $-80^{\circ} \mathrm{C}$ freezer. Families were given a $\$ 25$ gift card for participation. For this secondary analysis, only samples from children whose parents consented for future research were used, and the data and samples were anonymized prior to analysis. At the time of the secondary analysis, samples were shipped on dry ice to the laboratory at the US Centers for Disease Control and Prevention. The initial study and secondary analysis were both approved by the Colorado Multiple Institutional Review Board; since families had consented for future research we did not need to reconsent.

\section{Measures}

After completing informed consent, parents had completed a questionnaire about their child's health, and demographics. Since birthdates were removed from the secondary dataset to ensure anonymity, we obtained patient age from the family census. Parent report of tobacco smoke exposure was assessed with the question: "Does anyone who lives in your home or who cares for your child smoke tobacco (yes or no)?" Parent report of marijuana smoke exposure was assessed after October 2014 with the question "Does anyone who lives in your home or who cares for your child smoke marijuana (yes or no)".

\section{Analysis of Urinary Marijuana Biomarkers}

Analysis for marijuana biomarkers was performed using the method by Wei et al.(12) Urine samples were equilibrated with isotopically labeled internal standards, deconjugated by enzymatic and alkaline hydrolysis, and extracted using C18 sorbent. The final extracts were concentrated and $10 \mu \mathrm{l}$ of each sample was injected into an ultrahigh performance liquid chromatograph and analyzed using tandem mass spectrometry under electrospray ionization mode (ESI-MS/MS). This method has limits of detection of $0.005,0.015$, and $0.009 \mathrm{ng} / \mathrm{ml}$ for the three metabolites tested: total urinary THC, COOH-THC, and $\mathrm{CBD}$, respectively.

\section{Analysis of Urinary Tobacco Biomarkers}

Urinary cotinine (COT) was analyzed using a modification of the method developed by Bernert et al.(13) After adding isotopically labeled internal standards to $200 \mu$ lof urine, the samples were hydrolyzed with $\beta$-glucuronidase, purified using supported liquid extraction, concentrated, and then taken up in $100 \mu \mathrm{l}$ water. A $5 \mu \mathrm{l}$ aliquot of this solution was injected into a ultrahigh performance liquid chromatograph and analyzed using atmospheric pressure chemical ionization tandem mass spectrometry. The limits of detection for COT was $0.030 \mathrm{ng} / \mathrm{ml}$. We used a cutoff of $2.0 \mathrm{ng} / \mathrm{ml}$ to identify children with likely household contact exposure, based on Matt et al.(8) Laboratory blank and quality control samples were simultaneously processed and analyzed to assure the quality of the analytical results (14).

\section{Data Analysis}

Chi square tests were done to assess bivariable differences, and all analyses were done using SAS, (SAS Institute, Cary, NC). For 10 subjects $(23 \%)$, there was more than one family member under 2 , making identification of the subjects' exact age difficult, so we performed two sensitivity analyses in which we assumed all of the missing participants were (i) in the younger age group and (ii) in the older age group; our results did not change significantly.

\section{RESULTS}

Of 180 eligible inpatients in the original study, we enrolled 99 (55\%); 86 were able to provide a urine sample. Of these, 43 agreed to the use of the urine for future research and had sufficient sample remained for the current analyses. Most (77\%) were male and $52 \%$ were less than 1 y of age (Table 1 ). Patients were predominantly white (79\%); $47 \%$ were of Hispanic ethnicity. All were residents of the state of Colorado, and $28 \%$ lived in multiunit housing. Of those who were screened for contact with marijuana or tobacco users $(N=25), 16 \%$ reported marijuana use in the home or by a caregiver and $28 \%$ reported tobacco use (Table 2). Total urine THC and CBD in all urine samples were below the detection limit; the THC metabolite 11-nor-9-carboxy-THC (COOH-THC) was detected in urine from $16 \%$ of patients. The range in $\mathrm{COOH}-\mathrm{THC}$ concentration was $0.03-1.5 \mathrm{ng} / \mathrm{ml}$, with two patients having levels $>1 \mathrm{ng}$ / $\mathrm{ml}$. Almost one quarter (23\%) had urine cotinine levels above $2.0 \mathrm{ng} / \mathrm{ml}$, suggesting household contact exposure.

There was no difference in $\mathrm{COOH}-\mathrm{THC}$ detection by gender, age, or living in multiunit housing (Table 1). Non-white children were more likely to have detectable $\mathrm{COOH}-\mathrm{THC}$ (44\%) compared to white children ( $9 \% ; P=0.026)$; there were no differences by ethnicity. Of those who reported contact with marijuana users, 75\% had detectable COOH-THC, compared to $10 \%$ of those who reported no exposure $(P<0.016)$.

Table 1. Comparison of demographics and detectable $\mathrm{COOH}-\mathrm{THC}$ in urine $(n=43)$

\begin{tabular}{|c|c|c|c|c|c|c|c|}
\hline \multirow{2}{*}{ Gender } & \multicolumn{6}{|c|}{$n, \%$} & \multirow{2}{*}{$\begin{array}{c}P \text { value } \\
0.173\end{array}$} \\
\hline & \multicolumn{2}{|c|}{$\begin{array}{l}\text { Overall } \\
(n=43)\end{array}$} & \multicolumn{2}{|c|}{$\begin{array}{c}\text { COOH- } \\
\text { THC- } \\
(n=36)\end{array}$} & \multicolumn{2}{|c|}{$\begin{array}{c}\text { СООН- } \\
\text { THC+ } \\
(n=7)\end{array}$} & \\
\hline Female & 10 & 23.3 & 10 & 100.0 & 0 & 0.0 & \\
\hline Male & 33 & 76.7 & 26 & 78.8 & 7 & 21.2 & \\
\hline Age (years) $(n=33)$ & & & & & & & 0.398 \\
\hline$<1$ & 17 & 51.5 & 15 & 88.2 & 2 & 11.8 & \\
\hline $1-2$ & 16 & 48.5 & 12 & 75.0 & 4 & 25.0 & \\
\hline Race & & & & & & & 0.026 \\
\hline White & 34 & 79.1 & 31 & 91.2 & 3 & 8.8 & \\
\hline Not white & 9 & 20.9 & 5 & 55.6 & 4 & 44.4 & \\
\hline Hispanic/Latino ethnicity & & & & & & & 0.421 \\
\hline No & 23 & 53.5 & 18 & 78.3 & 5 & 21.7 & \\
\hline Yes & 20 & 46.5 & 18 & 90.0 & 2 & 10.0 & \\
\hline Race/ethnicity & & & & & & & 0.076 \\
\hline White & 20 & 46.5 & 17 & 85.0 & 3 & 15.0 & \\
\hline Hispanic/Latino ethnicity & 20 & 46.5 & 18 & 90.0 & 2 & 10.0 & \\
\hline Other & 3 & 7.0 & 1 & 33.3 & 2 & 66.7 & \\
\hline Multiunit housing & & & & & & & 0.378 \\
\hline No & 31 & 72.1 & 27 & 87.1 & 4 & 12.9 & \\
\hline Yes & 12 & 27.9 & 9 & 75.0 & 3 & 25.0 & \\
\hline
\end{tabular}

11-nor-9-carboxy-THC (COOH-THC). 
Table 2. Comparison of reported exposure to marijuana and tobacco and detectability of $\mathrm{COOH}-\mathrm{THC}$ and cotinine in urine $(n=43)$

\begin{tabular}{|c|c|c|c|c|c|c|c|}
\hline & & & & & & & \\
\hline & Ove & $(n=43)$ & $\mathrm{COOH}$ & $(n=36)$ & COOI & $C+(n=7)$ & $P$-value \\
\hline No & 21 & 84.0 & 19 & 90.5 & 2 & 9.5 & \\
\hline Yes & 4 & 16.0 & 1 & 25.0 & 3 & 75.0 & \\
\hline Yes & 12 & 27.9 & 8 & 66.7 & 4 & 33.3 & \\
\hline Dichotomized urinary cotinine using $2.0 \mathrm{ng} / \mathrm{mL}$ cutoff $(n=39)$ & & & & & & & 0.004 \\
\hline No & 30 & 76.9 & 28 & 93.3 & 2 & 6.7 & \\
\hline Yes & 9 & 23.1 & 4 & 44.4 & 5 & 55.6 & \\
\hline
\end{tabular}

11-nor-9-carboxy-THC (COOH-THC).

Urinary $\mathrm{COOH}-\mathrm{THC}$ and cotinine were also positively associated; of those with a urine cotinine of $>2.0 \mathrm{ng} / \mathrm{ml}, 56 \%$ had detectable $\mathrm{COOH}-\mathrm{THC}$, compared to $7 \%$ of those with lower tobacco smoke exposure $(P<0.004)$. While the prevalence of detectable COOH-THC was higher after legalization (21 vs. $10 \%$ prior), this difference was not statistically significant.

\section{DISCUSSION}

This is the first study to demonstrate the presence of THC metabolites in children exposed to marijuana smoke. While documenting the presence of metabolites of THC in children does not imply causation of disease, it does suggest that, like tobacco smoke, marijuana smoke is inhaled by children in the presence of adults who are using it. High sensitivity testing will give us the opportunity to study the effects of secondhand marijuana smoke on children's health more effectively, and researchers and funders should prioritize these investigations. National surveys such as NHANES offer opportunities to track trends in secondhand marijuana smoke exposure, as they do for secondhand tobacco smoke. In the interim, parents should be cautioned not to smoke marijuana in the presence of their children.

In our study, there was a relationship between detectable $\mathrm{COOH}-\mathrm{THC}$ and having a urinary cotinine level $>2.0 \mathrm{ng} / \mathrm{ml}$, indicating that children exposed to marijuana smoke were also more likely to be exposed to tobacco smoke, which increases their risk for cognitive deficits (15) and respiratory illness (4). More study is warranted to investigate if marijuana smoke exposure adds additional risk. This research will help inform appropriate educational materials and outreach to parents and caregivers who use both marijuana and tobacco in the presence of their children.

Parent report of marijuana exposure was strongly associated with detection of urinary COOH-THC. While we had initially suspected that social desirability bias would lead to underreporting of exposure, this finding suggests that a parent report screening question would be useful for institutions in areas where marijuana is legal. Parents who report household marijuana smoking could then be counseled on safe use around children. It is still possible that the screening question is underestimating use, and further research is needed to understand whether the marijuana use is taking place in the presence of the child, or whether the exposure could represent third-hand exposure.

\section{Limitations}

There are several limitations to this study. As we were working with limited samples remaining from a prior study, we have a very small sample size. We had insufficient power to be able to determine additional associations, such as with illness severity, or to complete more quantitative associations, and thus it has limited external validity. Since this was a secondary analysis on previously collected samples, we were unable to assess additional demographic, socioeconomic status, and other factors that may have been associated with marijuana use. Since we could only analyze the samples from those with consent for future research, it is possible that there was bias towards nonmarijuana using families in the sub-sample, and thus the true proportion of exposed children could be higher. We did not assess for medical use of marijuana in these children specifically, but since we enrolled only previously healthy children, medicinal marijuana use would be highly unlikely. We are also unable to assess whether the exposure was from secondhand marijuana smoke vs. neonatal transmission or breastfeeding; however the fact that our exposure rate was similar in the $<1$ $\mathrm{y}$-old age group as the 1-2-y-old age group would suggest that the detectable $\mathrm{COOH}-\mathrm{THC}$ is more likely from the secondhand smoke. Finally, this is a sample of children hospitalized for bronchiolitis in Colorado, and the findings may not be generalizable to other populations.

\section{Conclusion}

Marijuana metabolites are detectable in young children with exposure to secondhand marijuana smoke. These children are exposed to the psychoactive compounds in marijuana, and are potentially at risk for negative health effects. More than half of children with tobacco smoke exposure were also exposed to marijuana. Understanding the health consequences of 


\section{Articles | wilson etal.}

marijuana smoke exposure in children is critical for providers, parents, and policymakers to best protect children from harmful exposures.

\section{STATEMENT OF FINANCIAL SUPPORT}

The study was funded by the Flight Attendant Medical Research Institute through a grant to the American Academy of Pediatrics' Julius B. Richmond Center of Excellence, The Children's Hospital Colorado Research Institute, and the Centers for Disease Control and Prevention. The findings and conclusions in this report are those of the authors and do not necessarily represent the views of the Centers for Disease Control and Prevention.

Disclosure: None of the authors have any conflicts of interest or financial relationships to disclose.

\section{REFERENCES}

1. SAMHS. Results from the 2013 National Survey on Drug Use and Health: Summary of National Findings. NSDUH Series H-48, HHS Publication No. (SMA) 14-4863. 2014. http://www.samhsa.gov/data/sites/default/files/ NSDUHresultsPDFWHTML2013/Web/NSDUHresults2013.pdf.

2. Schauer GL, King BA, Bunnell RE, Promoff G, McAfee TA. Toking, vaping, and eating for health or fun: marijuana use patterns in adults, U.S., 2014..Am J Prev Med 2016; 50:1-8.

3. Wei B, Alwis KU, Li Z, et al. Urinary concentrations of PAH and VOC metabolites in marijuana users. Environ Int 2016;88:1-8.

4. Moritsugu KP. The 2006 Report of the Surgeon General: the health consequences of involuntary exposure to tobacco smoke. Am J Prev Med 2007:32:542-543.

5. Moir D, Rickert WS, Levasseur G, et al. A comparison of mainstream and sidestream marijuana and tobacco cigarette smoke produced under two machine smoking conditions. Chem Res Toxicol 2008;21:494-502.
6. Owen KP, Sutter ME, Albertson TE. Marijuana: respiratory tract effects. Clin Rev Allergy Immunol 2014;46:65-81.

7. Wang X, Derekhshandeh R, Narayan S, et al. One minute of marijuana secondhand smoke exposure substantially impairs vascular endothelial function. J Am Heart Assoc 2016; 5:e003858.

8. Cone EJ, Bigelow GE, Herrmann ES, et al. Nonsmoker exposure to secondhand cannabis smoke. III. Oral fluid and blood drug concentrations and corresponding subjective effects. J Anal Toxicol 2015;39: 497-509.

9. Matt GE, Quintana PJ, Hovell MF, et al. Households contaminated by environmental tobacco smoke: sources of infant exposures. Tob Control 2004;13:29-37.

10. Schauer GL, Berg CJ, Kegler MC, Donovan DM, Windle M. Assessing the overlap between tobacco and marijuana: Trends in patterns of couse of tobacco and marijuana in adults from 2003-2012. Addict Behav 2015;49:26-32

11. Ammerman S, Ryan S, Adelman WP; Committee on Substance Abuse, the Committee on Adolescence. The impact of marijuana policies on youth: clinical, research, and legal update. Pediatrics 2015;135:e769-85.

12. Wei B, Wang L, Blount BC. Analysis of cannabinoids and their metabolites in human urine. Anal Chem 2015;87:10183-7.

13. Bernert JT Jr, Turner WE, Pirkle JL, et al. Development and validation of sensitive method for determination of serum cotinine in smokers and nonsmokers by liquid chromatography/atmospheric pressure ionization tandem mass spectrometry. Clin Chem 1997;43:2281-91.

14. Caudill SP, Schleicher RL, Pirkle JL. Multi-rule quality control for the agerelated eye disease study. Stat Med 2008;27:4094-106.

15. Yolton K, Dietrich K, Auinger P, Lanphear BP, Hornung R. Exposure to environmental tobacco smoke and cognitive abilities among U.S. children and adolescents. Environ Health Perspect 2005;113:98-103. 